\title{
A Study on the Character Type and Job Satisfaction of Dental Hygiene
}

\author{
Seung Hui Choi \\ Department of Dental Hygiene, Catholic Sangji College, Andong, Korea
}

Objective: This research aims to identify the job satisfaction level of dental hygienists working in dental hospitals and clinics using the engram personality analysis tool developed to understand the personality of individuals, and to create a dental hygienist ability development program to use it as basic data that can include personality characteristics in dental hygienists' major advanced education.

Methods: The subjects of this study were selected among 60 dental hygienists working in dentists, dental hospitals, and general hospitals as those who understood the purpose of this study and agreed in writing to participate in the study, and 55 out of 60 were used in the final analysis, except for inappropriate research. The data collection period was from March to June 2020.

Results: If you take a look at the job satisfaction level of dental hygienists organized by personality type, the nine personality types of dental hygienists ranked satisfaction the highest with 32 (58 percent) in the middle of the day. Type 9 (mediators) and type 1 (reformers) were the highest with $15(27 \%)$ respectively, while dental hygienists' job satisfaction was the highest with 3.92 percent, and their job satisfaction was 3.67, their senior satisfaction was 3.58, their promotion satisfaction was 3.34 and their wage satisfaction was the lowest. Dental hygienists' job satisfaction by personality type averaged 3.78 among all loyalties of type 6 and 3.74 for mediators of type 9 with high job satisfaction. The four-type artist was the lowest at 2.786.

Conclusion: As a result of this study, we propose repeated studies within various fields and classes in the future. Subsequent studies to verify the effects are also suggested.

Keywords: character type, job satisfaction

\section{Introduction}

\section{Need for research}

\section{Corresponding author Seung Hui Choi}

E-mail: chsh3918@csj.ac.kr

(iD) https://orcid.org/0000-0002-5967-1875

Received May 28, 2021, Revised June 3, 2021, Accepted June 24, 2021
With industrial development and economic growth, people's values and goals in life have changed dramatically. where economic and physical safety are guaranteed, the higher desire for love, respect, desire for belonging, etc. will gradually increase. When a person is satisfied with the work of his or her organization, he or she becomes interested in the organ-

Copyright (C) 2021. Korean Academy of Preventive Dentistry. All rights reserved.

This is an Open Access article distributed under the terms of the Creative Commons Attribution Non-Commercial License (http://creativecommons.org/licenses/ by-nc/4.0) which permits unrestricted non-commercial use, distribution, and reproduction in any medium, provided the original work is properly cited. 
ization's goals and voluntarily puts his or her maximum capabilities into it. In addition, he/she will be positively aware of his/her workplace and duties, and furthermore, his/her relationship will be smooth, which will lead to productivity improvement [1].

Dental hygienists are those who prevent and educate oral diseases, clinical eaters who perform preventive measures before oral diseases occur, and oral health educators who provide education for oral health improvement and oral hygiene management. $70 \%$ of dental hygienists are employed in dental hospitals and clinics, and play an important role in dental institutions [2]. Recently, as hospitals and clinics have become large due to joint opening, the abilities required by dental hygienists have changed widely and diversely not only as simple as technology and functions as in the past, but also as partners in management [3].

Therefore, through the personality types classified by Aniogram, we would like to examine the job satisfaction of dental hygienists in changing clinical trials. The eneagram categorizes human personality types into three groups: instinctive, emotional, and thought types, which in turn relate to the centers of the body: the intestine, the chest, and the head. Thus, in the theory of eniagram, a total of nine personalities typify human character [4]. Lee [5] said that job satisfaction is caused by emotional reactions to job conditions, such as wages, management, and job content. Satisfaction is an emotional response, so the meaning of the concept can be grasped through mental reasoning, so job satisfaction is defined from various perspectives depending on the researcher. Herzberg [6] said that human attitudes are strongly influenced by their status within the group structure and by the nature of the structure itself, and the cohesion of the group depends on the extent to which members are drawn into the group. Kim [7] said that Using Eniagram's personality analysis tool, it analyzes hospital nurses' personality types and compares the differences in job satisfaction, organizational immersion and exhaustion among nurse groups by personality type in relation to professional development. In the eneagram, people do not stick to a particular personality type, and when they face up to what each personality type complements, they seek to develop as a professional by looking at job satisfaction in terms of a guide to what unhealthy aspects of each personality disappear [8].

Therefore, this study uses an eniagram personality analysis tool completed to understand the personality of an individual to find out the personality type job satisfaction level of dental hygienists working in dental hospitals and clinics. In practice, it is intended to develop into a professional profession by presenting characteristics that enhance the job satisfaction of dental hygienists. Furthermore, we will create a dental hygienist ability development program and use it as a basic data to include personality characteristics in the education of dental hygienists' majors.

\section{Materials and Methods}

\section{Research design}

This study was used to find out the personality type job satisfaction of dental hygienists working in dental hospitals and clinics, and to find out the personality characteristics of dental hygienists in practice.

\section{Collection of research subjects and data}

The subjects of this study were 60 dental hygienists working at dentists, dental clinics, and general hospitals who understood the purpose of this study and agreed to participate in it in writing, and 55 out of 60 were used for final analysis. The data collection period was from March to June 2020.

\section{Research tools}

1) Korean enneagram personality type tool [9]

The characteristics of personality types were used by Yoon [9] in the 1996 edition of the Riso-Hudson Enneagram, which was verified through the feasibility and standardization process in consideration of the cultural foundation of Korea Enneagram Personality Type Indicatrs (KEPTI). On a five-point scale of a total of 81 questions, a scale of "Not at all" to "Very Yes" from one point to five points, the corresponding score was written in a square column of the answer sheet for the eniagram test. Among the 81 questions, the highest score was determined as the type of librarian's personality by adding the score in the square and filling in the blank of A-I. There are nine types of personality: 1 type: reformer, 2 type: helper, 3 type: agitator, 4 type: artist, 5 type: thinker, 6 type: loyalist, 7 type: omnipotence, 8 type: leader, 9 type: mediator. In turn, based on Plato's three forces, emotion, intelligence, and will, the heart center (emotional center), type 2,3,4, and head center (thought center): type 5,6,7, type, and enteric center (intellectual center): type 8,9 and 1 .

\section{2) Job satisfaction tool [10]}

The questionnaire on job satisfaction is Used by Park [10], except for similar questions among the 23 questionnaires used in the research paper on job satisfaction, organizational immersion, and relationship between job performance of university library librarians; this study used 4 questions for job satisfaction, 2 questions for promotion, 3 questions for senior satisfaction, and 14 questions for wage satisfaction. On a 
five-point scale of a total of 14 questions, the higher the score from one "very dissatisfied" to five "very satisfied", the higher the job satisfaction.

\section{Data analysis method}

In this study, the statistical package used for statistical analysis is analyzed with the IBM SPSS Win 21.0 program.

1) We identify the frequency of the general characteristics of the subject.

2) Identify the frequency of the personality types of the experimental group.

3) Identify the t-test for the job, promotion, colleagues, superiors, and satisfaction by wage of the experimental group.

4) One-way batch variance analysis and post-validation of job satisfaction by personality type of experimental group shall be determined.

Table 1. Typical characteristics of the target $(\mathrm{N}=55)$

\begin{tabular}{|c|c|}
\hline Variable & $\begin{array}{c}\text { Experimental group } \\
\mathrm{n}(\mathrm{or} \mathrm{M})(\%, \mathrm{SD})\end{array}$ \\
\hline \multicolumn{2}{|l|}{ Sex } \\
\hline$M$ & $3(5.5)$ \\
\hline $\mathrm{F}$ & $52(94.5)$ \\
\hline \multicolumn{2}{|l|}{ Marriage } \\
\hline Married & $22(40.0)$ \\
\hline Unmarried & $33(60.0)$ \\
\hline \multicolumn{2}{|l|}{ Age } \\
\hline $20 s$ & $30(54.5)$ \\
\hline $30 \mathrm{~s}$ & $11(20.0)$ \\
\hline $40 s$ & $11(20.0)$ \\
\hline $50 \mathrm{~s}$ & $3(5.5)$ \\
\hline \multicolumn{2}{|l|}{ Career } \\
\hline Less than 5 years & $24(43.6)$ \\
\hline 6-10 years & $13(23.6)$ \\
\hline $11-15$ years & $9(16.4)$ \\
\hline $16-20$ years & $6(10.9)$ \\
\hline More than 25 years & $3(5.5)$ \\
\hline \multicolumn{2}{|l|}{ Academic background } \\
\hline Associate degree & $32(58.2)$ \\
\hline Bachelor & $5(9.1)$ \\
\hline Master & $9(16.4)$ \\
\hline Doctor & $9(16.4)$ \\
\hline \multicolumn{2}{|l|}{ Workplace type } \\
\hline Dental office & $47(85.5)$ \\
\hline Dental hospital & $7(12.7)$ \\
\hline General hospital & $1(1.8)$ \\
\hline \multicolumn{2}{|l|}{ Position } \\
\hline Dental hygienist (medical) & $39(70.9)$ \\
\hline Manager (counseling) & $3(5.5)$ \\
\hline Head of staff & $8(14.5)$ \\
\hline Total manager (management) & $5(9.1)$ \\
\hline Total & $55(100.0)$ \\
\hline
\end{tabular}

\section{Results}

\section{Typical characteristics of the target}

If you look at the general characteristics of this study, gender was $94.5 \%$ (52) for women and 3\% (3) for men. Marriage was found to be $40 \%$ married and $60 \%$ (33) unmarried. There are $54.5 \%$ (30 people) in their $20 \mathrm{~s}, 20 \%$ (11 people) in their $30 \mathrm{~s}, 20 \%$ (11 people) in their $40 \mathrm{~s}$, and $5.5 \%$ ( 3 people) in their $50 \mathrm{~s}$ and older. In terms of experience, $43.6 \%$ ( 24 people) in less than five years, $23.6 \%$ (13 people) in 6-10 years, $16.4 \%$ (9 people) in $11-15$ years, $10.9 \%$ (6 people) in 16-20 years, and $5.5 \%$ (3 people) in 25 years or more. Professional bachelor's degrees were $58.2 \%$ (32), 9.1\% (5), and $16.4 \%$ (9), respectively. The highest number of dentists was 85.5 percent (47), The positions were $70.9 \%$ (39) of dental hygienists, $5.5 \%$ (3) managers, $14.5 \%$ (8 personnel-related) managers, and $9.1 \%$ (5) personnel-related) managers (Table 1).

\section{Personality type of dental hygienist}

The nine personality types of dental hygienists showed that intestinal centers (intuition centers) were the highest at 32 (58\%). Type 9: Mediator and Type 1: Reformer was the highest with 15 (27\%), 6 types of loyalists $10(8 \%) ; 2$ types: helper 6 (12\%); 7 types: all-around 3 (5\%); 3 types: agitator and 8 types: leader 2 (4\%); 4 types: artist and 5 types: thinker $1(2 \%)$ (Table 2).

\section{Dental hygienist job, promotion, colleagues, superiors, satisfaction by wage}

Looking at the job satisfaction of dental hygienists, peer satisfaction was the highest at 3.92, job satisfaction was 3.67, senior satisfaction was 3.58, promotion satisfaction was 3.34, and wage satisfaction was the lowest at 3.17 (Table 3).

Table 2. Personality type of dental hygienist $(N=55)$

\begin{tabular}{clcc}
\hline $\begin{array}{c}\text { Strength-centered } \\
\text { personality type }\end{array}$ & 9 Personality types & $\begin{array}{c}9 \text { Personality } \\
\text { frequencies } \\
(\%)\end{array}$ & $\begin{array}{c}\text { Strength- } \\
\text { centered } \\
\text { frequencies } \\
(\%)\end{array}$ \\
\hline Heart center & 2 types: Helper & $6(12)$ & $9(16)$ \\
(emotion center) & 3 types: Agitator & $2(4)$ & \\
& 4 types: Artist & $1(2)$ & \\
Head center & 5 types: Thinker & $1(2)$ & $14(25)$ \\
(accident center) & 6 types: Loyalist & $10(18)$ & \\
& 7 types: Omnipotence & $3(5)$ & \\
Colon center & 8 types: Leader & $2(4)$ & $32(58)$ \\
(intuition center) & 9 types: Mediator & $15(27)$ & \\
& 1 types: Reformer & $15(27)$ &
\end{tabular}




\section{Job satisfaction by personality type of dental hygienist}

The job satisfaction level of dental hygienists by personality type was found to be high, with 6 types of loyalists averaging 3.78, and 9 types of mediators averaging 3.74. Next, Type 3 agitators, Type 8 leaders, Type 1 reformers, Type 2 assistants, Type 5 thinkers, Type 7 multi-talented and Type 4 artists were the lowest at 2.786 (Table 4).

\section{Discussion}

When a dental hygienist is satisfied with his or her organization's work, he or she becomes interested in the organization's goals and voluntarily exerts his or her full capacity. In addition, she will be positively aware of his/her workplace and duties, and furthermore, her relationship will be smooth, which will lead to productivity improvement. The reason for moving to work was that it was inappropriate treatment with human relationships, and among those who had not yet experienced turnover, they considered moving due to inadequate treatment, uncomfortable relationships with superiors, and inability to perform their own social awareness [11]. In the enigma, a person does not stick to a particular personality type, and when he or she is confronted with what each personality type supplements, he or she is given a guide on how unhealthy aspects of each personality disappear. It intends to develop as a professional by presenting characteristics of dental hygienists who enhance job satisfaction in clinicians.

If you look at the general characteristics of this study, gender was $94.5 \%$ (52) for women and 3\% (3) for men. Married $40 \%$ (22), unmarried 60\% (33), 20s 54.5\% (30 people), 30s $20 \%$ (11 people), 40 s $20 \%$ (11 people), 50 s or older is $5.5 \%$. In terms of experience, $43.6 \%$ (24 people) in less than five years, $23.6 \%$ (13 people) in 6-10 years, $16.4 \%$ (9 people) in $11-15$ years, $10.9 \%$ (6 people) in $16-20$ years, and $5.5 \%$ (3 people) in 25 years or more. Professional bachelor's degrees were $58.2 \%$

Table 3. Dental hygienist job, promotion, colleagues, superiors, satisfaction by wage $(\mathrm{N}=55)$

\begin{tabular}{lcccc}
\hline \multicolumn{1}{c}{ Variable } & Average & $\begin{array}{c}\text { Standard } \\
\text { compilation }\end{array}$ & $\mathrm{t}$ & $\mathrm{p}$ \\
\hline Job satisfaction & 3.67 & 0.64 & 42.25 & ${ }^{*} 0.00$ \\
Promotion satisfaction & 3.34 & 0.84 & 29.29 & ${ }^{*} 0.00$ \\
Peer satisfaction & 3.92 & 0.54 & 53.63 & ${ }^{*} 0.00$ \\
Higher satisfaction & 3.58 & 0.76 & 35.00 & ${ }^{*} 0.00$ \\
Wage satisfaction & 3.17 & 0.05 & 22.48 & ${ }^{*} 0.00$ \\
\hline
\end{tabular}

$* \mathrm{p}<0.05$.
(32), 9.1\% (5), and 16.4\% (9), respectively. The highest number of dentists was $85.5 \%$ (47), The positions were $70.9 \%$ (39) of dental hygienists, 5.5\% (3) managers, 14.5\% (8personnel-related) managers, and 9.1\% (5 personnel-related) managers (Table 1). According to Kang [12]'s study, organizational immersion averaged 3.38 points overall, and the older the age, the older the married, the longer the number of years of service and the higher the income, the significant difference.

If you look at the nine personality types of dental hygienists, The center of the intestine was the highest at 32 (58 percent). Type 9: Mediator and Type 1: Reformer was the highest with $15(27 \%), 6$ types of loyalists $10(8 \%) ; 2$ types: helper 6 (12\%); 7 types: all-around 3 (5\%); 3 types: agitator and 8 types: leader 2 (4\%); 4 types: artist and 5 types: thinker $1(2 \%)$ (Table 2). According to Yoon [8], Jang-hyung focuses his energy on his instincts, basic functions of life, and what he hopes for with his will and strength, and says that they have a lot of anger underlying self-defending behavior. According to Lee [13], the personality type of dental hygienists had the highest breast type with $63(38 \%)$ and the lowest head type with 61 (36.7\%) and long type with $42(25.5 \%)$, It turned out to be different from the original.

If you look at the job satisfaction of a dental hygienist, Peer satisfaction was the highest with 3.92 , job satisfaction was 3.67 , senior satisfaction was 3.58 , promotion satisfaction was 3.34, wage satisfaction was the lowest with 3.17 (Table 3). In this study, $54.5 \%$ (30 people) in their 20 s showed the highest peer satisfaction with 3.92, Wage satisfaction was the lowest at 3.17. In general characteristics, $85.5 \%$ (47) of dentists participated, indicating the lowest wage satisfaction. According to Yoon [14], the overall average of dental hygienists' emotional labor at dental institutions was 2.75 on a four-point scale, indicating that they are under stress, This is said to have

Table 4. Job satisfaction by personality type of dental hygienist $(\mathrm{N}=55)$

\begin{tabular}{|c|c|c|c|c|c|}
\hline \multirow[b]{2}{*}{ Variable } & \multirow[b]{2}{*}{9 Personality types } & \multicolumn{4}{|c|}{ Standard } \\
\hline & & Average & $\begin{array}{l}\text { compi- } \\
\text { lation }\end{array}$ & $\mathrm{F}$ & $\mathrm{p}$ \\
\hline Job & 2 types: Helper & 3.571 & 0.3077 & & \\
\hline \multirow[t]{8}{*}{ satisfaction } & 3 types: Agitator & 3.643 & 0.4041 & & \\
\hline & 4 types: Artist & 2.786 & . & & \\
\hline & 5 types: Thinker & 3.398 & . & & \\
\hline & 6 types: Loyalist & 3.786 & 0.5771 & 0.949 & $* 0.05$ \\
\hline & 7 types: Omnipotence & 3.179 & 0.8864 & & \\
\hline & 8 types: Leader & 3.624 & 0.4546 & & \\
\hline & 9 types: Mediator & 3.748 & 0.4315 & & \\
\hline & 1 types: Reformer & 3.583 & 0.5150 & & \\
\hline
\end{tabular}

$* \mathrm{p}<0.05$. 
a low educational background in relation to emotional labor, a general hospital, a wage of less than 22 million won to 28 million won, and emotional labor was high in the case of smoking.

The job satisfaction level of dental hygienists by personality type was found to be high, with 6 types of loyalists averaging 3.78, and 9 types of mediators averaging 3.74. Next, Type 3 agitators, Type 8 leaders, Type 1 reformers, Type 2 assistants, Type 5 thinkers, Type 7 multi-talented and Type 4 artists were the lowest at 2.786 (Table 4). According to Yoon [8], Type 6 is a loyal person who values trust in himself and others, and is diligent and responsible for what he has done, with 3.78 points for job satisfaction, Type 4 is an artist who likes meditation, while he was passive in everything, his job satisfaction was the lowest with 2.78 points due to his romantic personality. The personality type, which accounted for the largest frequency by personality type of dental hygienist, was 15 (27\%) mediators of type 9 , with a high job satisfaction of 3.75 points, Fifteen ( 27 percent) of the first-type reformers were also found to have moderate job satisfaction of 3.59. According to Lee [13]'s research, the cross-analysis of the type of eneagram and the number of turnover, there is no difference in the number of enegrams for the three types of enegrams, which can be attributed to the lack of complaints about the job, The number of years of service for dental hygienists varies by personality type. According to Kang [12]'s study, regression analysis to identify factors that significantly affect job satisfaction, organizational immersion and turnover of dental hygienists working at dentists showed that job satisfaction has a significant impact on job satisfaction, According to Park [10], analyzed the impact of the librarian's personal situation factors on job satisfaction, organizational immersion, and job performance, and certificates and positions affected job satisfaction, and gender, age, and position affected the degree of organizational immersion. It was also analyzed that age, qualification, and position affect the level of job performance. The higher the level of satisfaction with the job itself, superiors, and wages, the higher the level of organizational immersion. Dental hygienists have generally shown low satisfaction due to low social treatment, imposition of inappropriate tasks on image and performance compared to strong pride in their abilities and work, which causes frequent turnover [15].

In response, this study aims to develop into a professional job by using an eniagram personality analysis tool completed to understand individual personality to find out the personality satisfaction of dental hygienists working at dental clinics and clinics. Furthermore, we will create a dental hygienist ability development program and use it as a basic data to include personality characteristics in the education of dental hygienists' majors.

\section{Conclusion}

In response, this study aims to develop into a professional profession by using an eniagram personality analysis tool to understand the personality of dental hygienists working at dental clinics and clinics.

1. If you look at the general characteristics of this study, Gender was $94.5 \%$ (52) for women and 3\% (3) for men, Married 40 percent (22), unmarried 60 percent (33), 54.5\% (30 people) in their 20s, 20\% (11 people) in their $30 \mathrm{~s}, 20 \%$ (11 people) in their $40 \mathrm{~s}$, and $5.5 \%$ (3 people) in their $50 \mathrm{~s}$ and older, In terms of experience, $43.6 \%$ (24 people) in less than five years, $23.6 \%$ (13 people) in 6-10 years, $16.4 \%$ (9 people) in $11-15$ years, $10.9 \%$ (6 people) in 16-20 years, and 5.5\% (3 people) in 25 years or more, Professional bachelor's degrees were $58.2 \%$ (32), 9.1\% (5), and 16.4\%(9), respectively. The highest number of dentists was 85.5 percent (47), The positions were $70.9 \%$ (39) of dental hygienists, $5.5 \%$ (3) managers, $14.5 \%$ ( 8 personnel-related) managers, and $9.1 \%$ ( 5 personnel-related) managers (Table 1).

2 . The nine personality types of dental hygienists showed that intestinal centers (intuition centers) were the highest at 32 (58\%). Type 9: Mediator and Type 1: Reformer was the highest with 15 (27\%), 6 types of loyalists 10 (8\%); 2 types: helper $6(12 \%) ; 7$ types: all-around 3 (5\%); 3 types: agitator and 8 types: leader 2 (4\%); 4 types: artist and 5 types: thinker 1 (2\%) (Table 2).

3. Looking at the job satisfaction of dental hygienists, peer satisfaction was the highest at 3.92, job satisfaction was 3.67, senior satisfaction was 3.58, promotion satisfaction was 3.34, and wage satisfaction was the lowest at 3.17 (Table 3).

4 The job satisfaction level of dental hygienists by personality type was found to be high, with 6 types of loyalists averaging 3.78, and 9 types of mediators averaging 3.74. Next, Type 3 agitators, Type 8 leaders, Type 1 reformers, Type 2 assistants, Type 5 thinkers, Type 7 multi-talented and Type 4 artists were the lowest at 2.786 (Table 4).

This study investigates the organizational structure, personality type, and job satisfaction that can stimulate dental hygienists' motivation and creativity, and furthermore, a dental hygienist ability development program to include personality characteristics in dental hygienist education.

As a result of the above, we propose iterative studies with various disciplines and classes in the future. It also proposes a follow-up study that verifies its effectiveness by applying it.

\section{Conflict of Interest}

No potential conflict of interest relevant to this article was reported. 


\section{ORCID}

Seung Hui Choi, https://orcid.org/0000-0002-5967-1875

\section{References}

1. Kim Young-kyung (2003). A study of job satisfaction and quality of life for dental hygienists. Korean Journal of Dental Hygiene Education 2003;3:127-41.

2. Jung Jae-yeon (1998): A Survey Study on Dental Hygiene's Turnover and Job Activity" Monthly Dental Study 1998;43.

3. Kang Bu-wol (1999). "An empirical study of causes and causes of tissue immersion - in dental hygienists...". A doctoral dissertation at Kyunggi University Graduate School 1999.

4. Yoon Un-sung (2004). Understanding and applying the eniagram 2004:16-8.

5. LEE Du lee. (2008). A study on the personality type and job satisfaction of librarians in college libraries. Korean Library and Information Society Journal 2008;39:119-38.

6. Herzberg. F(1986). Motivation and hygiene theory. Kim Young-sik and Joo Sam-hwan. Bae Young-sa (Seoul). p.11-3.

7. Kim Hee-kyung (2005). "Comparison of personality types and job satisfaction, organizational immersion and exhaustion of hospital nurses using eniagram." Clinical nursing research $2005 ; 11.119$.
8. Yoon Un-sung (2000). Examination of personality test of eniagram and use of it as a company. Korean Journal of Adult Education 2000;3:203-24.

9. Yoon Un-sung (2007). KEPTI (Korean Eniagram Personality Type Test). Korea Neagram Education Research Institute. 2007.

10. Park Hyun-jung (2007). A study on the relationship between job satisfaction, organizational immersion, and job performance of librarians in university libraries. Master's thesis at Sungkyunkwan University. 2007:67-8.

11. Lee Sun-mi, A Study on Job Satisfaction by Workplace of Dental Hygiene, Dongnam University of Health, 1998;16.

12. Kang Ok Hee (2004). A study of the effects of turnover on dental hygienists. Dentists in Seoul and Gyeonggi Province. Yonsei University Graduate School of Health and Environment. 2004.

13. Lee Jung-woo (2010). The effect of personality analysis of dental hygienists using MBTI and eniagram on the number of turnover and years of service. It's the Korea Dental Association. 2010;48:738-53.

14. Yoon Sung-wook et al. (2011). Relationship between emotional labor and sleep health according to personality types of dental hygienists in some areas. Korea Dental Hygiene Society 2011; 11:243-9.

15. Lim Hae-kyung, a study on the turnover of dental hygienists, Kyung Hee University Graduate School of Public Administration, 2001. 